\title{
Clinical and Prognostic Analysis of Hypopharyngeal Squamous Cell Carcinoma with Synchronous and Metachronous Multiple Malignancies
}

\author{
KEISUKE YAMAMOTO, KENICHI TAKANO, ATSUSHI KONDO, \\ MAKOTO KUROSE, KAZUFUMI OBATA and TETSUO HIMI
}

\author{
Department of Otolaryngology, Sapporo Medical University School of Medicine, Sapporo, Japan
}

\begin{abstract}
Background/Aim: To analyze the clinical features and prevalence of synchronous and metachronous second primary malignancies (SPMs) in patients with hypopharyngeal squamous cell carcinoma (HSCC), their associated risk factors, and cause-specific mortality. Patients and Methods: We retrospectively reviewed 136 patients treated with curative intent at our hospital. Statistical analyses were performed to determine factors predictive of SPM and cause-specific mortality. Results: Sixty-three of 136 patients (46.3\%) developed SPM; of these, 41 (30.1\%) and $42(30.9 \%)$ had synchronous and metachronous SPMs, respectively, with patient overlap. The most common site of synchronous and metachronous SPMs was the oesophagus ( $65.8 \%$ and $24.4 \%$, respectively); the corresponding overall survival rates were $34.1 \%$ and $66.5 \%$, respectively. Furthermore, heavy drinking was significantly correlated with synchronous SPM $(p<0.001)$. Conclusion: Oesophageal cancer surveillance is recommended for patients with HSCC, especially heavy drinkers. Our findings may help identify and properly manage HSCC patients at high risk of SPMs.
\end{abstract}

Hypopharyngeal squamous cell carcinoma (HSCC) exhibits clinical manifestations that are different from other head and neck cancers. While it is less prevalent than other head and neck SCCs, accounting for 3-5\% of all such malignancies, it carries a very poor prognosis (1-3). High mortality due to HSCC is caused not only by the high rates of nodal and early

This article is freely accessible online.

Correspondence to: Dr. Kenichi Takano, Department of Otolaryngology, Sapporo Medical University School of Medicine, S1W16, Chuo-ku, Sapporo 060-8556, Japan. Tel: +81 116889655, Fax +81 116155405, e-mail: kent@ sapmed.ac.jp

Key Words: Hypopharyngeal cancer, synchronous cancer, squamous cell carcinoma, oesophageal cancer. systemic metastases at presentation or during follow-up, but also the occurrence of second primary malignancies (SPMs) that are identified either simultaneously with the primary lesion (synchronous) or a period of time thereafter (metachronous). A recent study found that $17 \%$ of 2,063 patients with head and neck cancer involved SPMs, and that the overall survival rates of these patients were significantly lower than in those without SPMs (4). The head and neck, lung, and oesophagus are the most frequent areas of SPM development after an index head and neck cancer $(4,5)$. Many of the common risk factors for head and neck cancer, such as smoking, alcohol, aging, and poor oral hygiene, can increase the risk for SPM elsewhere in the body. Patients with HSCC in particular develop SPMs more frequently than those with other primary regions of head and neck cancer $(5,6)$; therefore, identifying the critical risk factors for this phenomenon is important for the earlier detection and prevention of multiple primary cancers. However, there have been few studies that focused on SPM in patients with HSCC. Hence, the present study aimed to analyse the clinical features and prevalence of synchronous and metachronous SPM in patients with HSCC, as well as to identify the risk factors associated with SPM occurrence and determine the causespecific mortality.

\section{Patients and Methods}

Patients. A total of 136 patients (121 men and 15 women) with HSCC were diagnosed and treated between 2006 and 2015 at the Department of Otolaryngology, Sapporo Medical University, Japan. The patients' median age was 67 years (range $=33-84$ years). Primary HSCC was diagnosed by otolaryngologists following clinical examinations and imaging. Pathological diagnosis was confirmed by the Department of Surgical Pathology at Sapporo Medical University. HSCC stage was classified according to the 7th edition of the International Union against Cancer tumour-nodemetastasis system. Inclusion criteria were primary biopsy-proven SCC (but not recurrent or multiple primary tumours), eligibility for curative radiotherapy, and availability for long-term follow-up data of at least 2 years. Exclusion criteria were previous malignancy before HSCC, previous chemotherapy, and/or previous radiotherapy 
treatment for non-cancer ailments. SPM arising from other organs were defined according to the criteria of Warren and Gates (7) as follows: 1) the tumors must be clearly malignant on histological examination, 2) the tumors must be separated by normal mucosa, and 3 ) the possibility that the second tumor represents metastasis must be excluded. We confirmed SPMs using biopsies; a synchronous SPM was defined as that which developed within 6 months of the index tumor diagnosis, while a metachronous SPM developed more than 6 months after initiating radiotherapy.

Assessment of smoking and alcohol consumption. The cumulative cigarette consumption was calculated in pack-years; which is defined as 20 cigarettes smoked every day for 1 year. We evaluated the drinking frequency and volume of alcohol intake according to beverage types. The amount was converted to ethanol (grams), and values for each beverage type were summed. The ethanol estimates for these calculations were as follows: $5 \%$ for beer, $15 \%$ for Japanese saké, $12 \%$ for wine, $35 \%$ for shochu (a distilled alcoholic beverage made in Japan), and $43 \%$ for whisky. The cumulative amount of alcohol consumption was then expressed as the saké index (weight $[\mathrm{g}] / 22 \mathrm{~g}$ of ethanol consumed per day multiplied by years of drinking). The traditional Japanese drinking unit, the gou, corresponds to $22 \mathrm{~g}$ of ethanol; thus, this index represents the total gou consumed per day multiplied by years of drinking.

Statistical analysis. All statistical analyses were conducted using the SPSS software (version 22.0J for Windows, IBM Corp., Armonk, NY, USA). The Fisher's exact test and Student's $t$-test were used to compare categorical variables and continuous variables, respectively. Survival outcomes were calculated using the KaplanMeier method and compared using the log-rank test. All $p$-values were 2 -sided, and $p>0.05$ was considered statistically significant.

\section{Results}

Clinical characteristics of HSCC with or without SPM. The clinical characteristics of patients in our study are shown in Table I. The patients were predominantly men, with an 8:1 ratio over women. The median follow-up duration of the surviving patients was 30 months (range $=3-124$ months). The index HSCC was located in the piriform sinus in $76.2 \%$ of patients, the posterior wall in $15.8 \%$, and the post-cricoid area in $5.7 \%$. Approximately three-quarters of the patients had nodal metastases at the time of diagnosis, and more than half had stage IV HSCC.

Distribution and survival outcomes of patients with SPM. Sixty-three of our patients $(46.3 \%)$ had SPMs; the most common site was the oesophagus $(27.2 \%)$, followed by the stomach $(10.3 \%)$, head and neck region $(7 \%)$, lung $(4.4 \%)$, and colon/rectum (4.4\%) (Table II). The most common type of oesophageal cancer was thoracic $(87.5 \%)$ followed by cervical $(6.3 \%)$. During the follow-up period, the 5-year overall survival rate for patients with HSCC was $54.8 \%$; this rate was lower in patients with SPM than in patients without (60.0\%, 95\% confidence interval [CI] 0.00-0.00] vs. 48.5\%), but the difference was not significant (Figure 1).
Table I. Characteristics of patients in the present study.

\begin{tabular}{|c|c|c|}
\hline Characteristics & No. of patients & $\%$ \\
\hline All cases & 136 & \\
\hline \multicolumn{3}{|l|}{ Gender } \\
\hline Male & 121 & \\
\hline Female & 15 & \\
\hline Median age, years (range) & $67.0(33-84)$ & \\
\hline Mean follow-up months (range) & $30(3-124)$ & \\
\hline \multicolumn{3}{|l|}{ Primary site } \\
\hline Piriform sinus & 106 & 76.2 \\
\hline Posterial wall & 22 & 15.8 \\
\hline Post-cricoid area & 8 & 5.7 \\
\hline \multicolumn{3}{|l|}{$\mathrm{T}$ classification } \\
\hline $\mathrm{T} 1$ & 20 & \\
\hline $\mathrm{T} 2$ & 53 & \\
\hline $\mathrm{T} 3$ & 32 & \\
\hline $\mathrm{T} 4$ & 31 & \\
\hline \multicolumn{3}{|l|}{$\mathrm{N}$ classification } \\
\hline NO & 36 & \\
\hline $\mathrm{N} 1$ & 22 & \\
\hline $\mathrm{N} 2$ & 75 & \\
\hline N3 & 4 & \\
\hline \multicolumn{3}{|l|}{ Overall TNM stage } \\
\hline Stage I & 7 & 5 \\
\hline Stage II & 20 & 14.4 \\
\hline Stage III & 25 & 18 \\
\hline Stage IV & 84 & \\
\hline \multicolumn{3}{|l|}{ Smoking } \\
\hline \multicolumn{3}{|l|}{ Yes } \\
\hline No & & \\
\hline
\end{tabular}

Table II. Distribution of second primary malignancies in patients with hypopharyngeal carcinoma.

\begin{tabular}{lcr}
\hline & No. of patients & $\%$ \\
\hline Second primary malignancies & & \\
Yes & 63 & 46.3 \\
Oesophagus & 37 & 27.2 \\
Stomach & 14 & 10.3 \\
Head \& Neck & 10 & 7.4 \\
Lung & 6 & 4.4 \\
Colorectal & 6 & 4.4 \\
Others & 9 & 6.6 \\
No & 73 & 53.7 \\
\hline
\end{tabular}

Of the patients with SPM, synchronous and metachronous lesions were detected in 41 patients $(49.4 \%)$ and 42 patients $(50.6 \%)$, respectively (Table III). In both types of cases, the most common site of SPM was the oesophagus followed by the stomach and head and neck regions. The 5-year overall survival rate of HSCC patients with synchronous SPM was significantly lower than in those with metachronous SPM 


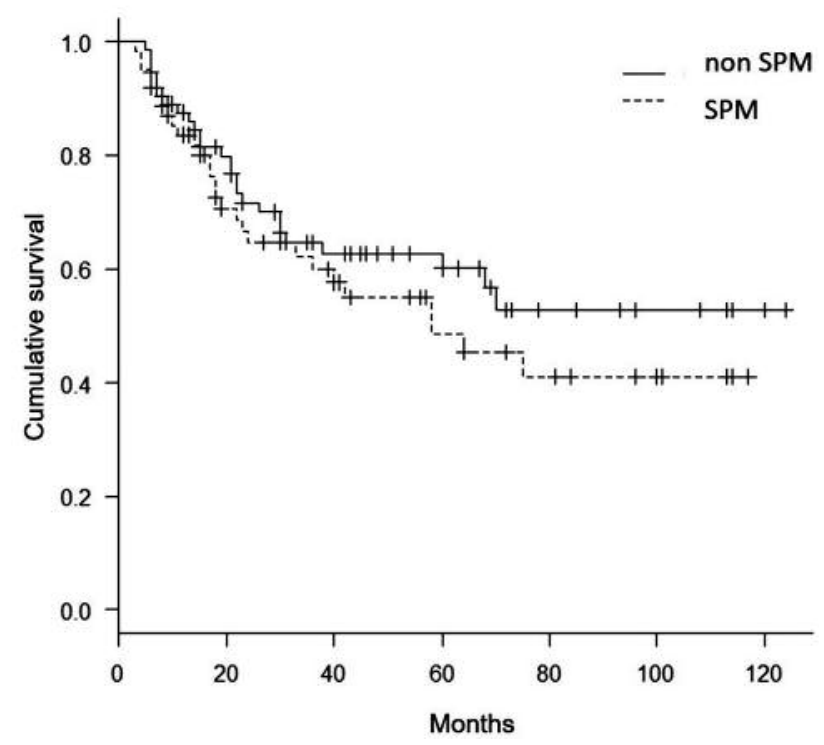

Figure 1. Comparison of overall survival rates according to the existence of second primary malignancies (log-rank $p=0.32)$.

(34.1\% [95\% CI $=0.15-0.54]$ vs. $65.5 \%$ [95\% CI $=0.42-0.83]$, $\log$-rank $p=0.013$ ) (Figure 2). On the other hand, the 5-year overall survival rate of HSCC patients with synchronous and metachronous oesophageal cancer was $40.3 \%(95 \% \mathrm{CI}=0.17$ $0.63)$ and $64.3 \%(95 \% \mathrm{CI}=0.25-0.87)$, respectively.

Comparing the characteristics of synchronous and metachronous SPM. We investigated the differences in risk factors between synchronous and metachronous SPMs. As shown in Table IV, age $(p=0.608)$, sex $(p=0.385), \mathrm{T}$ and $\mathrm{N}$ classification ( $p=0.115$ and $p=0.782$, respectively), tumor stage ( $p=0.763)$, smoking quantity $(p=0.515)$, and the Adult Comorbidity Evaluation-27 ( $p=0.237)$ were not significantly different. Only the amount of alcohol consumption was significantly associated with synchronous SPM development $(p<0.001)$.

\section{Discussion}

Although SPM has been recognized as the leading cause of long-term mortality in patients with head and neck cancer (58 ), to our knowledge, ours is the first study to specifically investigate mortality and risk factors in hypopharyngeal tumor index sites that are associated with the development of SPM. The risk of SPM in head and neck cancer is related to the level of exposure of the upper aerodigestive tract to environmental carcinogens, and is also thought to involve field cancerization (9). Recently, Rennemo et al. reported

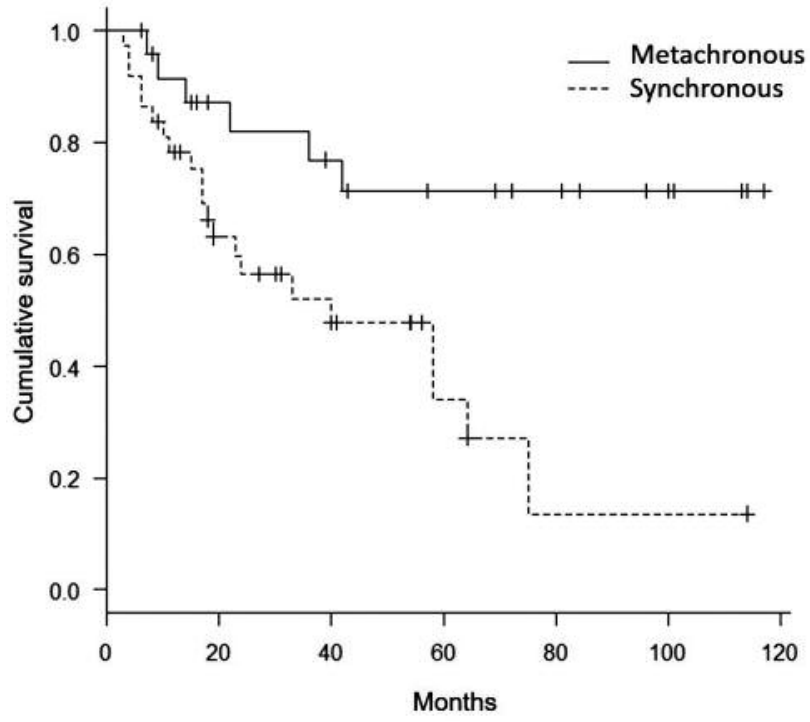

Figure 2. Comparison of overall survival rates in patients with synchronous versus metachronous second primary malignancies (log-rank $p=0.013)$.

Table III. Distribution of synchronous and metachronous second primary malignancies in patients with hypopharyngeal carcinoma.

\begin{tabular}{|c|c|c|c|c|}
\hline Sites & \multicolumn{2}{|c|}{ Patients } & \multicolumn{2}{|c|}{$\%$} \\
\hline Synchronous & \multicolumn{2}{|c|}{41} & \multicolumn{2}{|c|}{49.4} \\
\hline Metachronous & \multicolumn{2}{|c|}{42} & \multicolumn{2}{|c|}{50.6} \\
\hline & \multicolumn{2}{|c|}{ Synchronous } & \multicolumn{2}{|c|}{ Metachronous } \\
\hline Sites & Patients & $\%$ & Patients & $\%$ \\
\hline Oesophagus & 27 & 65.8 & 10 & 24.4 \\
\hline Stomach & 7 & 17.0 & 8 & 19.5 \\
\hline Head \& Neck & 4 & 9.8 & 6 & 14.6 \\
\hline Lung & 0 & 0 & 4 & 14.6 \\
\hline Colorectal & 2 & 4.9 & 4 & 9.8 \\
\hline Others & 1 & 2.4 & 8 & 20.0 \\
\hline
\end{tabular}

that $17 \%$ of patients with head and neck cancer had SPM, and that the overall survival rates of these patients were significantly lower than those in the patients without SPM (4). The early detection and management of SPM are suggested to improve overall survival rates in patients with HSCC (5).

In the present study, oesophageal cancer was the most common SPM in patients with HSCC, which is consistent with previous findings $(4-6,10)$. Since oesophageal cancer shows a 


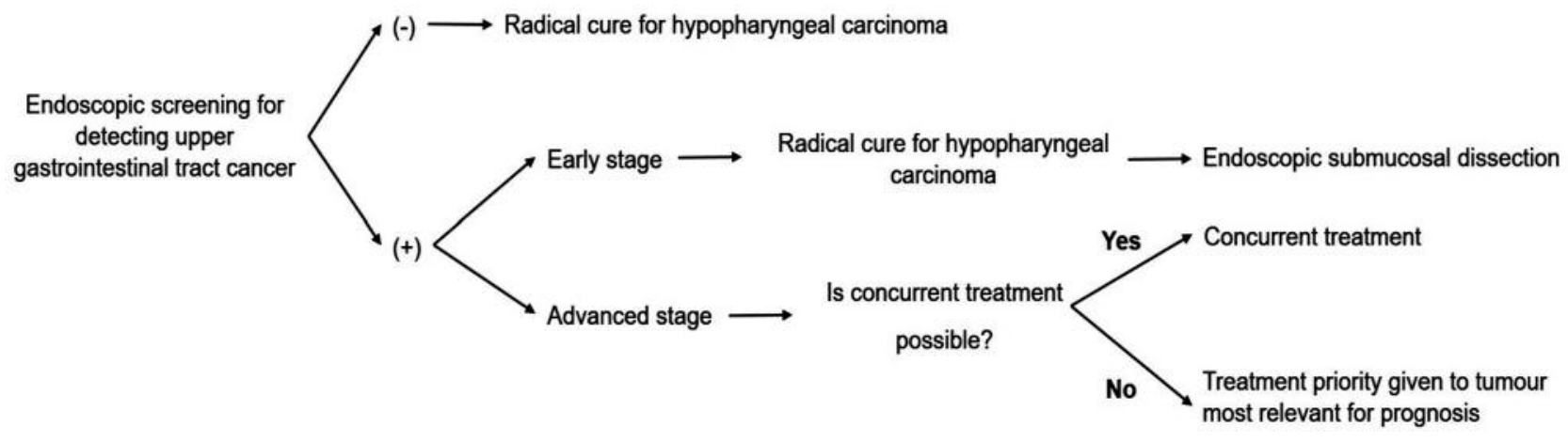

Figure 3. Our medical chart for oesophageal duplicated cancers in patients with hypopharyngeal cancer. All patients underwent upper endoscopic surveillance; in those with no oesophageal cancer detected by screening, curative treatment of hypopharyngeal carcinoma was performed. In patients with early oesophageal cancer, curative treatment of hypopharyngeal cancer was performed after the endoscopic treatment of oesophageal cancer. In patients with advanced oesophageal cancer, the relevant clinical departments were consulted regarding the availability of concurrent treatment. If concurrent treatment was possible, both the hypopharyngeal and oesophageal cancers were treated. If concurrent treatment proved challenging, treatment priority was administered to treat the tumor that had a greater impact on prognosis.

much poorer outcome than head and neck cancer, oesophageal cancer stage was found to be a crucial prognostic factor, including for HSCC patients with SPM. Therefore, it is critical to accurately diagnose SPMs in patients with HSCC. We routinely performed endoscopic screening for upper gastrointestinal tract cancer in all patients with HSCC (Figure 3 ). It has been demonstrated that routine endoscopic screening is effective for the early detection of oesophageal cancer, which in turn results in less invasive treatments such as endoscopic submucosal dissection (ESD) (11). Recent advances in narrow band imaging (NBI) and Lugol chromoendoscopy (LCE) have been particularly useful for the early detection of oesophageal cancer, which can then be treated by ESD (12). NBI and LCE, along with conventional endoscopy, are recommended for the diagnosis of early oesophageal cancer and to evaluate the potential of developing SPM in patients with HSCC. On the other hand, several studies have reported the usefulness of fluorodeoxyglucose-positron emission tomography/computed tomography (FDG-PET/CT) for the detection of SPM $(13,14)$. Although FDG-PET/CT is useful for detecting multiple SPMs, the reliability of this modality's ability to identify early oesophageal cancer is unclear; moreover, the sensitivity of FDG-PET/CT for detecting synchronous oesophageal cancer is reported to be relatively low $(15,16)$.

Synchronous and metachronous oesophageal cancer were found in $65.8 \%$ and $24.4 \%$ of patients with HSCC in our study, respectively. In other words, oesophageal cancer was the most frequent synchronous SPM in our patients. On the other hand, metachronous SPM sites in our patients tended to be systemic. Heavy alcohol consumption was the only variable that predicted a greater probability of synchronous SPM in patients with HSCC compared to metachronous SPM. This
Table IV. Risk factors for the development of second primary malignancies in patients with hypopharyngeal carcinoma.

\begin{tabular}{llccc}
\hline & & Synchronous & Metachronous & $p$-Value \\
\hline \multirow{2}{*}{ Gender } & Male & 35 & 22 & 0.385 \\
& Female & 2 & 3 & \\
Age & $\geq 70$ & 9 & 16 & 0.608 \\
& $<70$ & 16 & 21 & \\
T & T1-2 & 18 & 17 & 0.115 \\
& T3-4 & 19 & 7 & \\
N & N0 & 11 & 9 & 0.782 \\
Stage & N1-3 & 26 & 16 & \\
& I-II & 8 & 7 & 0.763 \\
Pack-year & III-IV & 29 & 18 & \\
& $<50$ & 25 & 13 & 0.515 \\
Sake index & $\geq 50$ & 7 & 6 & \\
\multirow{4}{*}{ ACE-27 } & $<50$ & 1 & 9 & $<0.001$ \\
& $\geq 50$ & 26 & 8 & \\
& $0-1$ & 25 & 21 & 0.237 \\
\hline
\end{tabular}

ACE: Adult comorbidity evaluation.

may be characteristic of patients in East Asian countries due to the slower metabolism of alcohol than in Western patients, which increases the toxic accumulation of acetaldehyde (1719). Previous studies in Japan indicated that $A L D H 2$ inactivation plays a crucial role in the susceptibility of the upper aerodigestive tract to multiple cancers $(20,21)$. Since drinking and smoking are known to show synergistic adverse effects, it is difficult to analyze each separately. However, a previous study that investigated patients who either drink or 
smoke, but not both, showed that smoking produces a risk of developing head and neck cancer in a volume-dependent manner. In contrast, alcohol produces a risk of head and neck cancers (in the oropharynx/hypopharynx and larynx) only when consumed heavily (22).

\section{Conclusion}

Physicians should be aware of the possible coexistence of SPMs in patients with HSCC, as these secondary malignancies were found in $46.3 \%$ of our patients. The survival rate of patients with HSCC who had synchronous SPM was significantly poorer than that in patients with metachronous SPM. Early detection of HSCC and proper intervention may lead to reduction of serious adverse events and mortality related to this disease. Endoscopic surveillance of the head and neck region is recommended in patients with HSCC to improve the early detection rates and treatments of both synchronous and metachronous SPMs, particularly in the oesophagus among heavy drinkers.

\section{Conflicts of Interest}

None.

\section{References}

1 Hall SF, Groome PA, Irish J and O'Sullivan B: The natural history of patients with squamous cell carcinoma of the hypopharynx. Laryngoscope 118: 1362-1371, 2008.

2 Cooper JS, Porter K, Mallin K, Hoffman HT, Weber RS, Ang KK, Gay EG and Langer CJ: National Cancer Database report on cancer of the head and neck: 10-year update. Head Neck 31: 748-758, 2009.

3 Chan JY and Wei WI: Current management strategy of hypopharyngeal carcinoma. Auris Nasus Larynx 40: 2-6, 2013.

4 Rennemo E, Zätterström U and Boysen M: Impact of second primary tumors on survival in head and neck cancer: an analysis of 2,063 cases. Laryngoscope 118: 1350-1356, 2008.

5 Lee DH, Roh JL, Baek S, Jung JH, Choi SH, Nam SY and Kim SY: Second cancer incidence, risk factor, and specific mortality in head and neck squamous cell carcinoma. Otolaryngol Head Neck Surg 149: 579-586, 2013.

6 Erkal HS, Mendenhall WM, Amdur RJ, Villaret DB and Stringer SP: Synchronous and metachronous squamous cell carcinomas of the head and neck mucosal sites. J Clin Oncol 19: 1358-1362, 2001 .

7 Warren S and Gates O: Multiple primary malignant tumors: a survey of the literature and statistical study. Am J Cancer 16: 1358-1414, 1932.

8 Jones AS, Morar P, Phillips DE, Field JK, Husband D and Helliwell TR: Second primary tumors in patients with head and neck squamous cell carcinoma. Cancer 75: 1343-1353, 1995.

9 Slaughter DP, Southwick HW and Smejkal W: Field cancerization in oral stratified squamous epithelium; clinical implications of multicentric origin. Cancer 6: 963-968, 1953.
10 León X, Quer M, Diez S, Orús C, López-Pousa A and Burgués $\mathrm{J}$ : Second neoplasm in patients with head and neck cancer. Head Neck 21: 204-210, 1999.

11 Gong EJ, Kim DH, Ahn JY, Choi KS, Jung KW, Lee JH, Choi KD, Song HJ, Lee GH, Jung HY, Kim JH, Roh JL, Choi SH, Nam SY and Kim SY: Routine endoscopic screening for synchronous esophageal neoplasm in patients with head and neck squamous cell carcinoma: a prospective study. Dis Esophagus 29: 752-759, 2016.

12 Wang WL, Lee CT, Lee YC, Hwang TZ, Wang CC, Hwang JC, Tai CM, Chang CY, Tsai SS, Wang CP, Ko JY and Lin JT: Risk factors for developing synchronous esophageal neoplasia in patients with head and neck cancer. Head Neck 33: 77-81, 2011.

13 Choi JY, Lee KS, Kwon OJ, Shim YM, Baek CH, Park K, Lee $\mathrm{KH}$ and Kim BT: Improved detection of second primary cancer using integrated $\left[{ }^{18} \mathrm{~F}\right]$ fluorodeoxyglucose positron emission tomography and computed tomography for initial tumor staging. J Clin Oncol 23: 7654-7659, 2005.

14 Strobel K, Haerle SK, Stoeckli SJ, Schrank M, Soyka JD, VeitHaibach $\mathrm{P}$ and Hany TF: Head and neck squamous cell carcinoma (HNSCC)--detection of synchronous primaries with 18F-FDG-PET/CT. Eur J Nucl Med Mol Imaging 36: 919-927, 2009.

15 Kondo N, Tsukuda M and Nishimura G: Diagnostic sensitivity of 18fluorodeoxyglucose positron emission tomography for detecting synchronous multiple primary cancers in head and neck cancer patients. Eur Arch Otorhinolaryngol 269: 15031507, 2012.

16 Hanamoto A, Takenaka Y, Shimosegawa E, Ymamamoto Y, Yoshii T, Nakahara S, Hatazawa J and Inohara H: Limitation of 2-deoxy-2-[F-18] fluoro-D-glucose positron emission tomography (FDG-PET) to detect early synchronous primary cancers in patients with untreated head and neck squamous cell cancer. Ann Nucl Med 27: 880-885, 2013.

17 Ohashi S, Miyamoto S, Kikuchi O, Goto T, Amanuma Y and Muto M: Recent advances from basic and clinical studies of esophageal squamous cell carcinoma. Gastroenterology 149: 1700-1715, 2015.

18 Yokoyama A, Muramatsu T, Omori T, Yokoyama T, Matsushita S, Higuchi S, Maruyama K and Ishii H: Alcohol and aldehyde dehydrogenase gene polymorphisms and oropharyngolaryngeal, esophageal and stomach cancers in Japanese alcoholics. Carcinogenesis 22: 433-439, 2001.

19 Yukawa Y, Ohashi S, Amanuma Y, Nakai Y, Tsurumaki M, Kikuchi O, Miyamoto S, Oyama T, Kawamoto T, Chiba T, Matsuda $\mathrm{T}$ and Muto M: Impairment of aldehyde dehydrogenase 2 increases accumulation of acetaldehyde-derived DNA damage in the esophagus after ethanol ingestion. Am J Cancer Res 4: 279-284, 2014.

20 Yokoyama A, Watanabe H, Fukuda H, Haneda T, Kato H, Yokoyama, T, Muramatsu T, Igaki H and Tachimori Y: Multiple cancers associated with esophageal and oropharyngolaryngeal squamous cell carcinoma and the aldehyde dehydrogenase-2 genotype in male Japanese drinkers. Cancer Epidemiol. Biomarkers Prev 11: 895-900, 2002.

21 Yokoyama A, Muramatsu T, Ohmori T, Makuuchi H, Higuchi S, Matsushita S, Yoshino K, Maruyama K, Nakano M and Ishii H: Multiple primary esophageal and concurrent upper aerodigestive tract cancer and the aldehyde dehydrogenase-2 genotype of Japanese alcoholics. Cancer 77: 1986-1990, 1996. 
22 Hashibe M, Brennan P, Benhamou S, Castellsague X, Chen C, Curado MP, Dal Maso L, Daudt AW, Fabianova E, Fernandez L, Wünsch-Filho V, Franceschi S, Hayes RB, Herrero R, Koifman S, La Vecchia C, Lazarus P, Levi F, Mates D, Matos E, Menezes A, Muscat J, Eluf-Neto J, Olshan AF, Rudnai P, Schwartz SM, Smith E, Sturgis EM, Szeszenia-Dabrowska N, Talamini R, Wei Q, Winn DM, Zaridze D, Zatonski W, Zhang ZF, Berthiller J and Boffetta P: Alcohol drinking in never users of tobacco, cigarette smoking in never drinkers, and the risk of head and neck cancer: pooled analysis in the International Head and Neck Cancer Epidemiology Consortium. J Natl Cancer Inst 99: 777-789, 2007.

Received October 9, 2017

Revised November 9, 2017 Accepted November 10, 2017 